\title{
Does an ecological advantage produce the asymmetric lineage ratio in a harvester ant population?
}

\author{
Deborah M. Gordon • Anna Pilko • Nicolas De Bortoli • \\ Krista K. Ingram
}

Received: 10 November 2012/Accepted: 15 May 2013/Published online: 29 May 2013

(c) The Author(s) 2013. This article is published with open access at Springerlink.com

\begin{abstract}
In dependent-lineage harvester ant populations, two lineages interbreed but are genetically distinct. The offspring of a male and queen of the same lineage are female reproductives; the offspring of a male and queen of different lineages are workers. Geographic surveys have shown asymmetries in the ratio of the two lineages in many harvester ant populations, which may be maintained by an ecological advantage to one of the lineages. Using census data from a long-term study of a dependent-lineage population of the red harvester ant, Pogonomyrmex barbatus, we identified the lineage of 130 colonies sampled in 1997-1999, ranging in age from 1 to 19 years when collected, and 268 colonies sampled in 2010, ranging in age
\end{abstract}

Communicated by Phil Lester.

D.M. Gordon, A. Pilko and K.K. Ingram contributed equally to this work.

Electronic supplementary material The online version of this article (doi:10.1007/s00442-013-2690-z) contains supplementary material, which is available to authorized users.

D. M. Gordon $(\bowtie) \cdot$ A. Pilko

Department of Biology, Stanford University, Stanford,

CA 94305-5020, USA

e-mail: dmgordon@stanford.edu

A. Pilko

e-mail: pilko@ucsd.edu

N. De Bortoli

Department of Biology, University of Namur, 5000 Namur, Belgium

e-mail: ndeborto@student.fundp.ac.be

K. K. Ingram

Department of Biology, Colgate University, Hamilton,

NY 13346, USA

e-mail: kingram@colgate.edu from 1 to 28 years when collected. The ratio of lineages in the study population is similar across an 11-year interval, $0.59 \mathrm{~J} 2$ in 1999 and $0.66 \mathrm{~J} 2$ in 2010. The rare lineage, J1, had a slightly but significantly higher number of mates of the opposite lineage than the common lineage, J2, and, using data from previous work on reproductive output, higher male production. Mature colonies of the two lineages did not differ in nest mound size, foraging activity, or the propensity to relocate their nests. There were no strong differences in the relative recruitment or survivorship of the two lineages. Our results show no ecological advantage for either lineage, indicating that differences between the lineages in sex ratio allocation may be sufficient to maintain the current asymmetry of the lineage ratio in this population.

Keywords Skewed lineage ratio - Pogonomyrmex . Sex ratio

\section{Introduction}

In most social insect species, whether a female becomes a reproductive or a sterile worker depends on how it is fed as a larva (Brian 1956). However, recent work on ants suggests that larval genotype can contribute to the determination of worker or reproductive status. An outstanding example is the dependent-lineage system of harvester ants in the genus Pogonomyrmex (Volny and Gordon 2002a; Helms Cahan and Keller 2003; Schwander et al. 2008; Anderson et al. 2009). There are two interbreeding but distinct lineages. The offspring of a male and queen of the same lineage are female reproductives; the offspring of a male and queen of different lineages are workers. A queen must produce workers to establish a successful colony that 
can raise reproductives. Thus, a queen must mate with males of both lineages to produce both reproductives and workers.

Female reproductives of Pogonomyrmex barbatus participate in a population-wide mating aggregation, and then the newly mated queens fly off, dig a nest, and found a colony. A queen can survive for 20-30 years (Gordon and Kulig 1998) producing all the workers, males, and gynes throughout the lifetime of the colony, using sperm stored from that original mating event. Because males are produced from unfertilized eggs, the frequency of males from each lineage is expected to be proportional to the frequency of queens and thus of colonies of each lineage in the population (Anderson et al. 2009). It appears that queens acquire sperm, on average, in a ratio that reflects relative proportions of each lineage (Helms Cahan and Julian 2010). A queen then produces workers and gynes in the ratio of lineages of the males with which she mated (Anderson et al. 2006; Schwander et al. 2006). Colonies begin to reproduce, sending out gynes and males to the annual mating flight, when the colony is about 5 years old (Gordon 1995) and has about 10,000 workers (Gordon 1992a). In colonies younger than 5 years, although queens may lay reproductive eggs in a ratio that corresponds to the lineage ratio of their mates, the reproductive eggs do not reach maturity (Helms Cahan et al. 2004; Clark et al. 2006; Schwander et al. 2006; Volny et al. 2006). Eventually, once the colony is large enough, and in response to physiological changes induced in the queens by exposure to winter cold (Schwander and Keller 2008), the reproductive brood is cared for until maturity and the colony sends reproductives to the annual mating flight. The colony continues to reproduce for the rest of its 25- to 30-year lifespan; there is no evidence for senescence in reproductive output (Wagner and Gordon 1999). Other work suggests a generation time of about 8 years (Ingram et al. 2013).

By analogy with the evolution of sex ratios (Seger and Stubblefield 2002), it would seem that the lineage ratio should be 1:1, providing each lineage with the same opportunity to mate with the other, so as to produce workers. Lineage ratios would be negatively frequencydependent if, for example, the more common lineage wastes too much effort producing and recycling reproductive eggs. However, lineage ratios have been sampled in many dependent-lineage populations, and the ratios are frequently skewed. For example, in other dependent-lineage populations of $P$. barbatus, in which the lineages are named $\mathrm{J} 1$ and $\mathrm{J} 2, \mathrm{~J} 2$ is more common than $\mathrm{J} 1$ (Anderson et al. 2006, 2011; Schwander et al. 2007). Such lineage asymmetries are likely to be strongly influenced by the difference between the two lineages in sex ratio allocation (Helms Cahan and Julian 2010; Anderson et al. 2011; Yamauchi and Yamamura 2006). The more common lineage produces more gynes, female reproductives, than the rare one, because the greater the proportion of colonies of the same lineage, the more the queens mate with males of the same lineage, and so more of their offspring are gynes. In contrast, the sex ratio of the reproductives produced by colonies of the rare lineage is biased toward males rather than gynes. Thus, as long as the rare lineage is able to secure enough mates of the same lineage to ensure fecundity by way of daughter queens that found new colonies, the asymmetrical lineage ratio can be maintained.

Models for the evolution of dependent-lineage systems have suggested that a basic mechanism for the stability of such asymmetries involves a balance of frequency-dependent selection at different stages of colony life history (Anderson et al. 2009, 2011). Young colonies of the rare lineage, with a higher proportion of mates of the opposite lineage, could produce a relatively larger number of workers; colonies of the common lineage, whose queens have a high proportion of mates of the same lineage, might produce fewer workers. High colony growth for young colonies of the rare lineage might promote colony survivorship. Some empirical tests support these predictions (Anderson et al. 2006) while others do not (Helms Cahan et al. 2010).

The abundance of dependent-lineage systems, and the fact that asymmetric ratios of lineages are geographically widespread, suggest that ecological factors may contribute to the stability of these populations (Anderson et al. 2006, 2011; Schwander et al. 2007; Helms Cahan et al. 2010). However, little is known about differences between the two lineages in colony growth, behavior, or survival in natural populations. Here, we present data on the history of a dependent-lineage population of about 300 colonies of $P$. barbatus. Because this population has been censused since 1985 and the ages of all colonies are known, it is possible to trace lineage-specific colony mortality rates, rates of colony founding, and the age distribution within lineages across generations.

First, we calculated the number of colonies on the site of each lineage using two large samples of colonies sampled at an interval of over 11 years, in 1997-1999 and 2010. We also used the data on colony age to determine the number of new colonies founded by each lineage in the two samples.

Second, we compared the two lineages in the frequency of mating with the opposite lineage and in the production of males and gynes. We also compared the sex ratio of alate reproductives in 95 colonies of known lineage for which alate reproduction was measured in 1997.

Next, we considered the possibility of an ecological advantage to one of the lineages. We tested whether the two lineages differ in nest mound area, because nest mound area has been used as a proxy for colony size. We compared the foraging behavior of the two lineages, because differences between the lineages in foraging behavior could influence colony survival or reproductive success. The seeds 
consumed by harvester ants are a limited resource (e.g., Davidson 1980), and colonies compete with conspecific neighbors for foraging area (Gordon 1992a; Gordon and Kulig 1996). A colony searches a large foraging area for seeds that are mostly distributed by wind and flooding; thus, seed patches are ephemeral (Gordon 1993). In drier years, when plants produce fewer seeds, colony mortality is high (Sanders and Gordon 2004) and more crowded colonies have lower reproductive output (Wagner and Gordon 1999).

Fourth, we examined the possibility that survival differs in the two lineages due to differences in their responses to changing ecological conditions, especially in rainfall, over the study period (Sanders and Gordon 2004). For the 130 colonies sampled in 1997-1999, 93 have now died, and we compared survivorship in the two lineages, by year and by age class, with Kolmogorov-Smirnov tests. Fifth, for the 268 colonies sampled in 2010, of which very few have died, we compared the age distributions of the two lineages.

Finally, we compared the frequency of nest relocation in the two lineages. About $10 \%$ of colonies relocate each year, and the same colonies tend to move repeatedly, and since there is no apparent effect on nearest-neighbor distances, it appears that relocation has some other function (Gordon 1992b). Because relocation may be costly, with a risk of predation and of desiccation while moving the queen and brood, a difference between the lineages in the tendency to move nests could be ecologically important.

\section{Methods}

We determined the lineages of two sets of colonies, one sampled in 1997-1999 and the second in 2010-2011. There were 130 colonies sampled in 1997-1999 that ranged in age from 1 to 19 years when collected. There were 268 colonies sampled in 2010 that ranged in age from 1 to 28 years when collected. All colonies were sampled at a long-term study site near Rodeo, New Mexico. Ages of the colonies were known from a census conducted each year since 1985, including some colonies that have been censused since 1981. Details of census methods are given in Gordon and Kulig (1996). Each year, all new colonies, founded the previous year and thus 1 year old, are added to the census, and all colony deaths are noted. The total number of colonies on the site each year is about 300 .

Genetic analysis

\section{Lineage ratio}

In 1997-1999 and in 2010, workers were collected, immersed in liquid nitrogen, and stored in $-80{ }^{\circ} \mathrm{C}$ for further analysis. To extract DNA, individual ants were pulverized and boiled in $200 \mu \mathrm{l}$ of $10 \%$ Chelex ${ }^{\circledR} 100$ (Bio-Rad) solution for $15 \mathrm{~min}$. Samples were centrifuged for $1 \mathrm{~min}$ and the supernatant used as a template for PCR amplification. Universal insect cox 1 primers modified for $P$. barbatus [forward C1-j-1751 (Pb) 5'-GGATCACCTGATATAGCATTCCC-3' and reverse $\mathrm{C} 1-\mathrm{N}-2191(\mathrm{~Pb}) 5^{\prime}$-CCAGGTAAAATTAA AATATAAACTTC- $\left.3^{\prime}\right]$ were used to amplify the 433-bp portion of the mitochondrial gene $\operatorname{cox} 1$ as in Helms Cahan and Keller (2003). All reactions were run in $25-\mu 1$ volumes with the following PCR conditions: $94{ }^{\circ} \mathrm{C}$ for $4 \mathrm{~min}$ followed by 35 cycles of $94{ }^{\circ} \mathrm{C}$ for $30 \mathrm{~s}, 48^{\circ} \mathrm{C}$ for $30 \mathrm{~s}$, and $72{ }^{\circ} \mathrm{C}$ for $90 \mathrm{~s}$ with a final cycle of $72{ }^{\circ} \mathrm{C}$ for $6 \mathrm{~min}$. PCR products were purified and then sequenced on both strands using dye-terminator chemistry using an ABI 3100 DNA sequencer (Applied Biosystems). Both forward and reverse strands were sequenced using fluorescent dyes. To classify the DNA haplotypes to one of the two lineages, J1 or J2, the phylogenetic positions of unique cox 1 sequence data were compared with previously defined J1 or J2 clades (Helms Cahan and Keller 2003; Anderson et al. 2006) using a neighbor joining topology in MEGA 5.0 computer program (Tamura et al. 2011).

\section{Microsatellite analysis}

We estimated mating frequencies for 263 of the 268 colonies sampled in 2010. We genotyped 20 workers per colony at five microsatellite loci $\mathrm{Pb} 5, \mathrm{~Pb} 6, \mathrm{~Pb} 7, \mathrm{~Pb} 8$, and $\mathrm{Pb} 9$ (Volny and Gordon 2002b). The primer sequences were redesigned to match the targeted flanking regions and modified with an M13 tag on the $5^{\prime}$ end of the forward primers and a 7-bp pigtail sequence (GTGTCTT) on the $5^{\prime}$ end of the reverse primers (Table 1).

PCR amplifications were performed in a $2-\mu$ f final volume containing $5 \mathrm{ng}$ of genomic DNA, $0.3 \mathrm{pmol} / \mu \mathrm{l}$ of M13tailed forward primer and "pig-tailed" reverse primer, $0.2 \mu \mathrm{l}$ $10 \times$ buffer, $0.1 \mu \mathrm{L} 50 \mathrm{mM} \mathrm{MgCl} 2,0.1 \mu \mathrm{l} 2 \mathrm{mM}$ dNTP, $0.04 \mu \mathrm{l}$ DMSO $100 \%, 0.02 \mu 10.5$ U Taq DNA polymerase (Qiagen), and $1.54 \mu \mathrm{l}$ water. Reactions were performed via a touchdown PCR, with an initial $5 \mathrm{~min}$ of denaturation at $95{ }^{\circ} \mathrm{C} ; 14$ cycles at $94{ }^{\circ} \mathrm{C}$ for $20 \mathrm{~s}$, annealing at $65^{\circ} \mathrm{C}$ for $20 \mathrm{~s}\left(0.5^{\circ} \mathrm{C}\right.$ decrease in each cycle $)$ and extension at $72{ }^{\circ} \mathrm{C}$ for $45 \mathrm{~s} ; 35$ cycles at $94{ }^{\circ} \mathrm{C}$ for $20 \mathrm{~s}, 58^{\circ} \mathrm{C}$ for $20 \mathrm{~s}$ and $72{ }^{\circ} \mathrm{C}$ for $45 \mathrm{~s}$; and final extension of $10 \mathrm{~min}$ at $72{ }^{\circ} \mathrm{C}$. Amplified fragments were analyzed on an ABI 3100 Genetic Analyzer (Applied Biosystems, Foster City, CA, USA) and sized using GeneMapper 4.1 and 400ROX size standard. All allele calls were manually verified. No multiplexing was attempted.

\section{Estimate of mating frequencies}

For each of the 263 colonies, we estimated the number of mates of the opposite lineage by estimating the number of 
Table 1 Primer sequences

Shown are F/R sequences of forward/reverse primers used to amplify the loci $\left(5^{\prime}-3^{\prime}\right.$ direction); range of allele sizes; number of alleles detected; $H_{\mathrm{o}}$ observed heterozygosity, $H_{\mathrm{e}}$ expected heterozygosity

\begin{tabular}{|c|c|c|c|c|c|}
\hline Locus & Primer sequences $5^{\prime}-3^{\prime}$ & Size range & Allele number & $H_{\mathrm{o}}$ & $H_{\mathrm{e}}$ \\
\hline $\mathrm{Pb} 5$ & $\begin{array}{l}\text { F: AACGCGAAAACAGAGCAGATT } \\
\text { R: GTCACGAAGGCTAGTGAGCTGT }\end{array}$ & $170-190$ & 16 & 0.972 & 0.742 \\
\hline $\mathrm{Pb} 6$ & $\begin{array}{l}\text { F: GGCAAGAGAGACTCTGTGTGAAA } \\
\text { R: GGATATGTGATACAGGCTGACGA }\end{array}$ & $234-270$ & 32 & 0.843 & 0.929 \\
\hline $\mathrm{Pb} 7$ & $\begin{array}{l}\text { F: CGACGATTAATTGAGCCAAGTC } \\
\text { R: TTATAATTCGCACGATCCAAGC }\end{array}$ & $365-395$ & 21 & 0.733 & 0.710 \\
\hline $\mathrm{Pb} 8$ & $\begin{array}{l}\text { F: CAAGGAACAGGACGTAGGTGAC } \\
\text { R: CTCAACGGAAAGGAAGAGGAAT }\end{array}$ & $265-395$ & 17 & 0.973 & 0.836 \\
\hline $\mathrm{Pb} 9$ & $\begin{array}{l}\text { F: GCATGCAAGCTGATGATGTTTATC } \\
\text { R: AAAAGCTCAGTTGTCAGCCTGT }\end{array}$ & $232-280$ & 30 & 0.972 & 0.897 \\
\hline
\end{tabular}

patrilines among the sampled workers. We reconstructed paternal genotype based on mother-offspring allele combinations by implementing the full likelihood approach in COLONY2 (Wang and Santure 2009). We measured the total number of inferred fathers in the sample of 20 workers from each colony for a total of 86 colonies of $\mathrm{J} 1$ and 177 of $\mathrm{J} 2$, and corrected the number of effective mates for small samples (Pamilo 1993) and for the uneven contribution of males to the offspring in the sample (Nielsen et al. 2003). We found the probability of failing to detect a paternal genotype, due to two fathers having the same genotype, based on the frequency of each allele at each locus (Boomsma and Ratnieks 1996) and then bootstrapped over those probabilities for all colonies to estimate $95 \%$ confidence intervals.

\section{Ecological measures}

To determine the ratio of the two lineages at two time points, sampled in 1997-1999 and 2010, we calculated the proportion of colonies of each lineage alive in that year. We determined the number of new 1-year-old colonies of each lineage that were founded at each census year. We compared the survivorship of the two lineages using the 130 colonies sampled in 1997-1999, of which 42 colonies of $\mathrm{J} 1$ and 51 colonies of $\mathrm{J} 2$ had died by 2011, and compared year-to-year changes in survivorship for the two lineages, using Kolmogorov-Smirnov tests. As another measure of differences between the lineages in mortality, we compared the age distributions of the lineages in the 268 colonies sampled in 2010. To determine whether the age distribution represented in our sample in 2010 was due to strong fluctuations in the contribution of each lineage from year to year, we compared the age distributions of the $\mathrm{J} 1$ and $\mathrm{J} 2$ colonies in 2010, with the age distributions in 2001 of those colonies sampled in 2010 that were alive in 2001, using a Kolmogorov-Smirnov test (Siegel 1956).

We used census records of nest relocation (determined as in Gordon 1992b) to compare with a Fisher's exact test the proportion of colonies of each lineage in the 268 colonies sampled in 2010 that had moved to a new nest at least once.

To compare the sex ratio allocation of the two lineages, we compared male and gyne production in 1997 (methods in Wagner and Gordon 1999) in 35 colonies of $\mathrm{J} 1$ and 60 colonies of $\mathrm{J} 2$, using two-tailed $t$ tests.

Nest mound area was measured in August 2011 in 29 mature colonies of $\mathrm{J} 1$ and 69 mature colonies of $\mathrm{J} 2$. The size of the nest mound was measured in two directions across the nest entrance, the longest diameter and the one perpendicular to the longest. Measurement extended to the edge of pebbles collected by the ants, or the edge of the midden of seed husks created by the ants (Sturgis et al. 2011). The area of the nest mound was calculated as the area of an ellipse with the two perpendicular measures halved as radii. The mean nest mound area of the two lineages was compared with a two-tailed $t$ test.

We compared foraging activity in the two lineages. Colonies show persistent, characteristic foraging activity (Gordon 1991; Gordon et al. 2011), though foraging activity varies from day to day (Gordon 1984; Gordon et al. 2008). Foraging activity was recorded for mature colonies, aged 5 years or more, in 57 colonies of $\mathrm{J} 2$ and 15 colonies of $\mathrm{J} 1$. We chose colonies that were clustered in four areas of about $150 \mathrm{~m}^{2}$ each within the site, to reduce any effects of microhabitat on foraging activity. Foraging activity was measured for 5 days in August 2011 as the mean number of foragers returning to the nest entrance in three consecutive 30-s observations, recorded during the peak of foraging activity between 0800 and 0900 hours. Foraging activity was recorded by eight observers, each of which always observed the same colonies each day. Observations of all 72 colonies were made simultaneously, within a 20-min period, to eliminate effects of time of day such as temperature. We found for each colony the mean foraging activity over 5 days. We compared for the two lineages the mean colony foraging activity over 5 days of observation using a two-tailed $t$ test. 


\section{Results}

The lineage ratio of $\mathrm{J} 2: \mathrm{J} 1$ remained relatively stable across 11 years. Using only the 130 colonies sampled in 1997-1999, the proportion of colonies that were J2 was 0.59 . Using only the 268 colonies sampled in 2010, many of which were alive in 1999 and earlier, the proportion of colonies that were $\mathrm{J} 2$ was 0.66 . The numbers of new colonies of each lineage varied from year to year, with more $\mathrm{J} 2$ than $\mathrm{J} 1$ colonies in all but 3 of the years between 1986 and 2011 (Fig. 1). Table 2 shows the numbers of colonies in the two samples that were alive in each year, using the data on colony age from the long-term census.

The proportion of all 1-year-old colonies each year on the site for which the lineage was known from both samples ranged from 0.29 (1 year old in 1989) to 1 (1 year old in 2002, 2006, 2008), with a mean proportion of 0.41 for colonies 1 year old in 1987-1997, and 0.74 for colonies 1 year old in 1998-2010. The proportion of all 1-year-old colonies that were included in our sample for a given year was less than 0.5 in 1987-1990, 1992-1994, and 1999.

Mating frequency with males of the opposite lineage is slightly but significantly higher in $\mathrm{J} 1$, the rare lineage, than in J2. Over all colonies sampled, the mean (SD) number of patrilines per colony, estimated from the worker genotypes, was 4.5 (1.42), $n=263$ colonies. The mean (SD) effective mating frequency, $M_{\mathrm{e}}$, was 3.32 (1.06), 3.95 (1.6) corrected for sample size as in Pamilo (1993), and 3.86 (1.5) corrected for unequal contributions of each male as in Nielsen et al. (2003). For J1, the mean (SD) number [using the corrected mean as in Nielsen et al. 2003) of mates of the opposite lineage was 4.16 (1.53) ( $n=86$ colonies); for $\mathrm{J} 2$ it was 3.72 (1.5) ( $n=177$ colonies); the means were significantly different $(t=1.97, p=0.03$, two-tailed $t$ test] (Table 3 ). The mean and bootstrapped probabilities of failing to detect a paternal genotype were 0.0032 and were

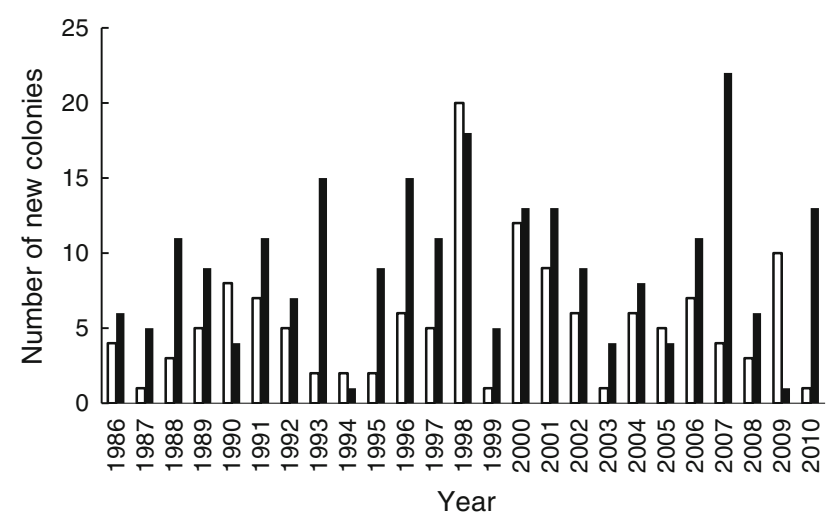

Fig. 1 One-year-old colonies of Pogonomyrmex barbatus by lineage. Open bars show the number of one-year-old J1 colonies in a given year, filled bars show the number of one-year-old colonies of $\mathrm{J} 2$ not significantly different; the $95 \%$ confidence interval around a difference of 0 between the two means was $-0.000005,0.00005$.

The lineages differed in male production but not in gyne production. Using data from 1997 on numbers of reproductives (Wagner and Gordon 1999) in colonies for which we identified the lineage, J1 produced significantly more males than $\mathrm{J} 2$ [mean (SD) for $\mathrm{J} 1=23.2$ (38.1), $n=35$; mean for $\mathrm{J} 2=8.9$ (17.8), $n=60 ; t=2.09, p<0.04$, two-tailed $t$ test]. There was no significant difference between the lineages in gyne production [mean (SD) for $\mathrm{J} 1=5.1(15.1)$, $n=35$; for $\mathrm{J} 2=7.8$ (19.1), $n=60 ; t=0.64, p=0.52$, two-tailed $t$ test). Though the numbers of alates produced by a colony sometimes reach hundreds, the means are low because some colonies produce few reproductives while others produce many (Wagner and Gordon 1999).

The two lineages did not differ in nest mound size. The mean (SD) nest mound area for 29 colonies of $\mathrm{J} 1$ was $2.82 \mathrm{~m}^{2}$ (1.69) and for 69 colonies of $\mathrm{J} 2$ was $2.27 \mathrm{~m}^{2}$

Table 2 History of lineage ratio of Pogonomyrmex barbatus colonies

\begin{tabular}{|c|c|c|c|}
\hline Years & $\begin{array}{l}\text { Number of } \mathrm{J} 1 \\
\text { colonies }\end{array}$ & $\begin{array}{l}\text { Number of } \mathrm{J} 2 \\
\text { colonies }\end{array}$ & $\begin{array}{l}\text { Proportion of colonies } \\
\text { that are } \mathrm{J} 2\end{array}$ \\
\hline 1986 & 12 & 19 & 61.29 \\
\hline 1987 & 13 & 24 & 64.86 \\
\hline 1988 & 16 & 35 & 68.63 \\
\hline 1989 & 21 & 44 & 67.69 \\
\hline 1990 & 29 & 48 & 62.34 \\
\hline 1991 & 36 & 59 & 62.11 \\
\hline 1992 & 41 & 66 & 61.68 \\
\hline 1993 & 43 & 81 & 65.32 \\
\hline 1994 & 45 & 82 & 64.57 \\
\hline 1995 & 47 & 91 & 65.94 \\
\hline 1996 & 53 & 106 & 66.67 \\
\hline 1997 & 58 & 117 & 66.86 \\
\hline 1998 & 78 & 135 & 63.38 \\
\hline 1999 & 78 & 140 & 64.22 \\
\hline 2000 & 85 & 142 & 62.56 \\
\hline 2001 & 91 & 146 & 61.60 \\
\hline 2002 & 91 & 155 & 63.01 \\
\hline 2003 & 90 & 154 & 63.11 \\
\hline 2004 & 95 & 158 & 62.45 \\
\hline 2005 & 98 & 159 & 61.87 \\
\hline 2006 & 100 & 166 & 62.41 \\
\hline 2007 & 100 & 186 & 65.03 \\
\hline 2008 & 99 & 186 & 65.26 \\
\hline 2009 & 106 & 185 & 63.57 \\
\hline 2010 & 102 & 196 & 65.77 \\
\hline
\end{tabular}

The table shows the number of colonies of each lineage alive in each year, using the ages of 130 colonies sampled in 1997-1999 and 268 colonies sampled in 2010-2011 
Table 3 Frequency of inter-lineage mating

\begin{tabular}{lllll}
\hline Lineage & $K_{\mathrm{obs}}$ & $M_{\mathrm{e}}$ & $M_{\mathrm{eP}}$ & $M_{\mathrm{eN}}$ \\
\hline $\mathrm{J} 1(n=86)$ & $4.83(1.42)$ & $3.54(1.05)$ & $4.26(1.62)$ & $4.16(1.53)$ \\
$\mathrm{J} 2(n=177)$ & $4.38(1.40)$ & $3.21(1.06)$ & $3.81(1.59)$ & $3.72(1.5)$ \\
Total & $4.52(1.42)$ & $3.32(1.06)$ & $3.95(1.6)$ & $3.86(1.52)$ \\
$(n=263)$ & & & & \\
\hline
\end{tabular}

Shown are $K_{\mathrm{obs}}$ the observed mean (SD) number of patrilines among workers, $n=$ number of colonies, $M_{\mathrm{e}}(\mathrm{SD})$ the effective number of patrilines inferred from paternity shares, $M_{\mathrm{eP}}(\mathrm{SD})$ the sample sizecorrected estimate of the queen's effective mating frequency and $M_{\mathrm{eN}}$ (SD) corrected for differences among males in contribution to worker offspring

(1.66); the two means were not significantly different ( $t=1.49, p=0.07$, two-tailed $t$ test,). The rare lineage, $\mathrm{J} 1$, had a higher proportion (0.14) of very large nests, more than $5 \mathrm{~m}^{2}$, than the more common lineage, J2 (0.08), but this was due to only a few nests.

The two lineages did not differ in foraging activity. The average colony mean (SD) rate of foraging per $30 \mathrm{~s}$, averaged over 5 days, for $15 \mathrm{~J} 1$ colonies was 34.6 (21.1), and for $57 \mathrm{~J} 2$ colonies was 31.1 (18.9). Mean foraging activity was not significantly different in the two lineages ( $t=-0.58, p \geq 0.28$, two-tailed $t$ test).

The two lineages did not differ in survivorship from 2000 to 2010 (Fig. S1). There was no difference in the age at death of $42 \mathrm{~J} 1$ and $51 \mathrm{~J} 2$ colonies sampled in 1997-1999 that subsequently died [mean (SD) age at death in $\mathrm{J} 1=13.4(5.8)$ years, in $\mathrm{J} 2=13.2(6.42)$ years, $t=0.16$, $d f=90, p=0.87$, two-tailed $t$ test). The distribution of survivorship for the colonies that died in the 1999 sample did not differ between the two lineages, either by year (Fig. S1) (Kolmogorov-Smirnov test, $D=0.33, p=0.43$ ) or by age class (Fig. S1) (Kolmogorov-Smirnov test, $D=0.27$, $p=0.20$ ). Comparing the age distributions of the 268 colonies sampled in 2010, the two lineages did not differ in age distribution in 2001 or 2010 (2001, $n$ for $\mathrm{J} 1=51, n$ for $\mathrm{J} 2=113, D=0.113$, ns; 2010, $n$ for $\mathrm{J} 1=87, n$ for $\mathrm{J} 2=187, \quad D=0.079$, ns; Kolmogorov-Smirnov test). This indicates there were no strong differences between lineages in survival to a given age past 1 year old, and no strong fluctuations in the relative recruitment of new, 1-year-old colonies of each lineage.

The two lineages did not differ in tendency to relocate nests. Of the 189 colonies of $\mathrm{J} 2,49(26 \%)$ had relocated nests at least once; of the 90 colonies of $\mathrm{J} 1,17$ (19 \%) had relocated their nests at least once (Fisher's exact test, $p=0.87$ ).

\section{Discussion}

The lineage ratio of the study population is biased toward $\mathrm{J} 2$. This result, from a large sample of colonies in a single dependent-lineage population of $P$. barbatus, is consistent with results from other studies with smaller samples in many populations that were sampled at a single point in time: while the extent of asymmetry in the lineage ratio varies, J2 tends to be the more common lineage (Schwander et al. 2007; Anderson et al. 2011).

The long-term census of this dependent-lineage population makes it possible for the first time to trace the lineage ratio across generations. The lineage ratio, J2:J1, has been stable at about 65:35 for over 11 years (about 1-2 generations; Ingram et al. 2013). As in other harvester ant dependent-lineage populations, the effective mating frequency with males of the opposite lineage was slightly but significantly higher in the rare lineage. We found that queens of both lineages are likely to mate with about four males of the opposite lineage. This result is similar to those reported by Helms Cahan and Julian (2010) in a laboratory study, in which the rare lineage had a slightly but not significantly larger mean number of mates of the opposite lineage. We did not measure the frequency of mating with males of the same lineage, so we do not know how the relative frequency of mates of the same and opposite lineage differs in the two lineages.

Our result that the rare lineage has more mates with the opposite lineage is consistent with the possibility that colonies of the rare lineage may produce more workers at the founding stage. In laboratory studies, newly-founded colonies of rare lineages initially produce more workers than those of the common lineage (Clark et al. 2006; Helms Cahan and Julian 2010), especially in the first few weeks (Schwander et al. 2006; Anderson et al. 2006), and lay a lower proportion of reproductive eggs (Schwander et al. 2006; Volny et al. 2006). However, in another laboratory study, early colony growth did not affect colony size after 1-2 years (Helms Cahan et al. 2010). The effects found in these laboratory studies on worker growth involve very small numbers of workers, from about 1 in the first 6 weeks to 10-20 workers per week in the older queens. Survival of founding colonies in our study population is very low (Gordon and Kulig 1996, 1998), but there are no data on the relationship between the number of workers in founding colonies and colony survival in natural populations. It is possible that one very effective worker might easily obtain as much food as many inept ones. Further work is needed to determine whether, in this population, founding colonies of the rare lineage are indeed larger and whether that affects colony survival.

If colonies of the rare lineage produce relatively more workers, because their queens mated with more males of the opposite lineage, the colonies could be larger when mature as well as at the founding stage. Our study provides no evidence that mature colonies of one lineage are larger than those of the other. Moreover, we found that the two 
lineages did not differ in nest mound size. It is important to note that there are no data showing an association of nest mound area and mature colony size in this species; this would require excavations to provide an independent measure of colony size. Slight differences among colonies in the extent to which they clear nest vegetation, in the opportunities for collecting pebbles from nearby abandoned mounds (Gordon, personal observation), and in damage to the nest that requires the colony to excavate more soil that makes the mound appear larger, could lead to differences in nest mound area that are not due to differences in colony size.

The hypothesis that larger initial colony size might provide an ecological advantage to the rare lineage is based on the premise that the larger the colony, the more food it obtains or the more effectively it competes with neighbors (e.g., Anderson et al. 2011). However, competition between neighboring colonies in $P$. barbatus depends not on a colony's size but on its level of foraging activity and the persistence with which it pursues the use of foraging areas that overlap with those of its neighbors (Gordon 1992a; Gordon and Kulig 1996; Adler and Gordon 2003). Foraging activity itself is not directly related to colony size; foraging activity changes markedly from day to day in the same colony (Gordon et al. 2008), while it takes many weeks to produce more workers. The clear, persistent differences among colonies in foraging activity (Gordon 1984, 1995; Gordon et al. 2008, 2011) arise from differences in how they regulate foraging in response to changing conditions.

Although there is no evidence that the two lineages differ in colony size, they might still differ in the regulation of foraging activity, leading colonies of one lineage to forage more than those of the other, independently of colony size. However, we found no evidence that colonies of one lineage forage more than those of the other. High and low foraging activity occurred in both lineages in a large sample of mature colonies. Thus, while there is considerable variation among colonies in foraging activity, there is no evidence that differences among colonies in foraging activity are associated with lineage.

Our results do not provide evidence for an ecological advantage for either lineage. However, we did not measure incipient colony success. Previous work shows that about $99 \%$ of gynes at the mating flight fail to found colonies that survive to be 1 year old (Gordon and Kulig 1996). The ratio of new 1-year-old colonies in the two lineages fluctuates from year to year (Fig. 1), and further study is needed to determine whether some factors that change from year to year may favor one lineage. We cannot rule out the possibility that small differences between the two lineages in the success of founding colonies may provide the selective advantage required for the rare lineage to persist when the lineage ratio is strongly asymmetric.
Our results do not support the hypothesis that an ecological advantage to one lineage helps to maintain the asymmetric lineage ratio in this population. First, nest recruitment in lineages fluctuates from year to year. This is not consistent with the hypothesis that the common lineage has higher fecundity; if it did, the frequency of new J2 nests should increase every year. Second, the same asymmetry in lineage ratio has been maintained in the course of strong fluctuations in ecological conditions. Such fluctuations include variation in rainfall and thus seed production, leading to fluctuations in food availability. Many studies show that food is limiting in harvester ant populations (e.g., Davidson 1980). Changes in the ecological conditions that affect food availability influence colony mortality (Sanders and Gordon 2004), intraspecific competition for food, and reproductive output (Wagner and Gordon 1999). From 1999 to 2010, there were strong fluctuations in conditions known to affect colony mortality, but there are no apparent differences between the lineages in relative survivorship across this time interval (Fig. S1). For example, while low rainfall in 1998 was associated with high colony mortality in 1999 (Sanders and Gordon 2004), 1999 was an equally poor year for both lineages in mortality, since the lineage ratio remained constant (Fig. S1). If in fact the slightly higher number of mates of the opposite lineage allows colonies of the rare lineage, J1, to grow more quickly, this did not lead to any difference between lineages in the relative number of colonies founded in 1999 to survive to be 12 -year-old colonies in 2010 . Thus, our results do not indicate that the lineages differ in response to the conditions that are ecologically important for this species.

The asymmetric lineage ratio in many populations (Schwander et al. 2007; Anderson et al. 2009, 2011), as well as in the study population discussed here, may be maintained primarily by sex ratio allocation (Yamauchi and Yamamura 2006; Anderson et al. 2009; Helms Cahan and Julian 2010), rather than by an ecological advantage to either lineage. In this population, it seems that the rare lineage, with only $35 \%$ of the colonies, is supplying about the same number of males per colony as the more common lineage. This is supported both by our data that show higher male production by the rare lineage, as in other populations (Anderson et al. 2009), and by our result that effective mating frequency with males of the opposite lineage is about the same for both lineages (Table 3). It is possible that, once the lineage ratio becomes skewed, for reasons that remain unexplained, the differences between the lineages in sex ratio allocation could cause the asymmetry to persist without any intrinsic ecological advantage to either lineage. The more common lineage produces relatively more gynes because there are more colonies of that lineage to produce gynes, and there are also more colonies to produce the males that provide these new gynes the 
opportunity to mate with males of the same lineage. The sex ratio of reproductives produced by the rare lineage may be male-biased because its queens have mated with fewer males of the same lineage and thus can produce fewer female reproductives (Anderson et al. 2009). This could allow queens of the common lineage to find enough males of the alternate lineage to produce workers, but would also make it more likely that there will be an excess of gynes of the more common lineage the following year, continuing the trend.

Over 11 years, the lineage ratio in this population appears stable at about $65: 35$ ratio of $\mathrm{J} 2: \mathrm{J} 1$. $\mathrm{J} 2$ is the most common lineage in many of the populations sampled (Schwander et al. 2007; Anderson et al. 2011). More longterm data are needed to determine whether the asymmetric lineage ratios found in other populations are stable. Small fluctuations in the production of rare-lineage gynes could make it impossible for the rare lineage to find enough mates of the same lineage to produce the gynes that establish new colonies. However, eventually, without some small advantage to the rare lineage, dependent-lineage populations with such asymmetries may go extinct.

Acknowledgments We thank Ximena Ampuero, James Hickman, LeAnn Howard, Noa Pinter-Wollman, Evie Pless, Andrew Merrell, and Claire Zabel for assistance in the measurement of nest size area and foraging rates. We thank Noa Pinter-Wollman, Shelby Sturgis, Sam Crow, and Andrew Merrell for help with collecting ants. We are grateful to the staff at the Southwestern Research Station for logistical support. The work was funded by NSF grant IOS-0718631 to D.M.G., and by further support from the Stanford Office of the Dean of Research and the Stanford Emergence of Cooperation project.

Open Access This article is distributed under the terms of the Creative Commons Attribution License which permits any use, distribution, and reproduction in any medium, provided the original author(s) and the source are credited.

\section{References}

Adler FR, Gordon DM (2003) Optimization, conflict and nonoverlapping foraging ranges in ants. Am Nat 162:529-543

Anderson KE, Holldobler B, Fewell JH, Mott BM, Gadau J (2006) Population-wide lineage frequencies predict genetic load in the seed-harvester ant Pogonomyrmex. Proc Natl Acad Sci USA 103:13433-13438

Anderson KE, Smith CR, Linksvayer TA (2009) Modeling the maintenance of a dependent lineage system: the influence of positive frequency dependent selection on sex ratio. Evolution 63:2142-2152

Anderson KE, Wheeler DE, Yang K, Linksvayer TA (2011) Dynamics of an ant-ant obligate mutualism: colony growth, density dependence and frequency dependence. Mol Ecol 20:1781-1793

Boomsma JJ, Ratnieks FLW (1996) Paternity in the eusocial Hymenoptera. Philos Trans R Soc Lond B 351:947-975
Brian MV (1956) Studies of caste differentiation in Myrmica rubra L. 4. Controlled larval nutrition. Insectes Soc 3:369-394

Clark RM, Anderson KE, Gadau J, Fewell JH (2006) Behavioral regulation of genetic caste determination in a Pogonomyrmex population with dependent lineages. Ecology 87:2201-2206

Davidson DW (1980) Some consequences of diffuse competition in a desert ant community. Am Nat 116:92-105

Gordon DM (1984) Species-specific patterns in the social activities of harvester ant colonies. Insectes Soc 31:74-86

Gordon DM (1991) Behavioral flexibility and the foraging ecology of seed-eating ants. Am Nat 138:379-411

Gordon DM (1992a) How colony growth affects forager intrusion in neighboring harvester ant colonies. Behav Ecol Sociobiol 31: $417-427$

Gordon DM (1992b) Nest relocation in the harvester ant, Pogonomyrmex barbatus. Ann Entomol Soc Am 85:44-47

Gordon DM (1993) The spatial scale of seed collection by harvester ants. Oecologia 95:479-487

Gordon DM (1995) The development of an ant colony's foraging range. Anim Behav 49:649-659

Gordon DM, Kulig AW (1996) Founding, foraging and fighting: colony size and the spatial distribution of harvester ant nests. Ecology 77:2393-2409

Gordon DM, Kulig AW (1998) The effect of neighboring colonies on mortality in harvester ants. J Anim Ecol 67:141-148

Gordon DM, Holmes S, Nacu S (2008) The short-term regulation of foraging in harvester ants. Behav Ecol 19:217-222

Gordon DM, Guetz A, Greene MJ, Holmes S (2011) Colony variation in the collective regulation of foraging by harvester ants. Behav Ecol 22:429-435

Helms Cahan S, Julian GE (2010) Shift in frequency-dependent selection across the life-cycle in obligately interbreeding harvester ant lineages. Evol Ecol 24:359-374. doi:10.1007/210 682-009-9311-7

Helms Cahan S, Keller L (2003) Complex hybrid origin of genetic caste determination in harvester ants. Nature 424:306-309

Helms Cahan S, Julian GE, Rissing SW, Schwander T, Parker JD, Keller L (2004) Loss of phenotypic plasticity explains genotypecaste association in harvester ants. Curr Biol 14:2277-2282

Helms Cahan S, Daly AB, Schwande T (2010) Genetic caste determination does not impose growth rate costs in Pogonomyrmex harvester ants. Funct Ecol 24:301-309

Ingram KK, Pilko A, Heer J, Gordon DM (2013) Colony life history and lifetime reproductive success of red harvester ant colonies. J Anim Ecol. doi:10.1111/1365-2656.12036

Nielsen R, Tarpy DR, Reeve HK (2003) Estimating effective paternity number in social insects and the effective number of alleles in a population. Mol Ecol 12:3157-3164

Pamilo P (1993) Polyandry and allele frequency differences between the sexes in the ant Formica aquilonia. Heredity 70:472-480

Sanders NJ, Gordon DM (2004) The interactive effects of climate and interspecific neighbors on mortality of red harvester ants. Ecol Entomol 29:632-637

Schwander T, Keller L (2008) Genetic compatibility affects queen and worker caste determination. Science 322:522

Schwander T, Helms Cahan S, Keller L (2006) Genetic caste determination in Pogonomyrmex harvester ants imposes costs during colony founding. J Evol Biol 19:402-409

Schwander T, Keller L, Helms Cahan S (2007) Two alternate mechanisms contribute to the persistence of interdependent lineages in Pogonomyrmex harvester ants. Mol Ecol 16: $3533-3543$

Schwander T, Humbert JY, Brent CS, Helms Cahan S, Chapuis L, Renai E, Keller L (2008) Maternal effect on female caste determination in a social insect. Curr Biol 18:265-269 
Seger J, Stubblefield JW (2002) Models of sex ratio evolution. In: Hardy ICW (ed) Sex ratios: concepts and research methods. Cambridge University Press, Cambridge, pp 2-25

Siegel S (1956) Nonparametric statistics for the behavioral sciences. McGraw-Hill, New York

Sturgis SJ, Green MJ, Gordon DM (2011) Hydrocarbons on harvester ant (Pogonomyrmex barbatus) middens guide foragers to the nest. J Chem Ecol 37:514-524. doi:10.1007/s10886-011-9947-y

Tamura K, Peterson D, Peterson N, Stecher G, Nei M, Kumar S (2011) MEGA5: molecular evolutionary genetics analysis using maximum likelihood, evolutionary distance, and maximum parsimony methods. Mol Biol Evol 28:2731-2739

Volny VP, Gordon DM (2002a) Genetic basis for queen-worker dimorphism in a social insect. Proc Natl Acad Sci USA 99:6108-6111
Volny VP, Gordon DM (2002b) Characterization of polymorphic microsatellite loci in the red harvester ant, Pogonomyrmex barbatus. Mol Ecol Notes 2:302-303

Volny VP, Greene MJ, Gordon DM (2006) Brood production and lineage discrimination in a harvester ant population with genetic caste determination. Ecology 87:2194-2200

Wagner D, Gordon DM (1999) Colony age, neighborhood density and reproductive potential in harvester ants. Oecologia 119:175-182

Wang J, Santure AW (2009) Parentage and sibship inference from multi-locus genotype data under polygamy. Genetics 181: 1579-1594

Yamauchi A, Yamamura N (2006) Persistence conditions of symmetric social hybridogenesis in haplo-diploid hymenoptera. J Theor Biol 240:24-31 